\title{
O JUS COGENS E O POSSÍVEL CONFLITO COM A SOBERANIA DO ESTADO
}

\author{
Luís Renato Vedovato \\ Doutor em Direito Internacional pela Faculdade de Direito da USP. Professor Doutor \\ da Universidade Estadual de Campinas (UNICAMP), em Campinas/SP. Professor da \\ Pontifícia Universidade Católica de Campinas, em Campinas/SP. Professor do Programa \\ de Mestrado em Direito da Universidade Metodista de Piracicaba (UNIMEP), em \\ Piracicaba/SP. E-mail: <Irvedovato@gmail.com>.
}

\section{Maria Carolina Gervásio Angelini}

Graduada em Direito pela Pontifícia Universidade Católica de Campinas, em Campinas/ SP. Advogada. E-mail: <ca_angelini@hotmail.com>.

Resumo: Os abusos e a falta de proteção ao homem, altamente evidenciada na I e II Guerras Mundiais, fez com que a dignidade humana se tornasse a principal preocupação da sociedade internacional. Um dos instrumentos que reconhece tal dignidade e protege direitos fundamentais do ser humano são as normas jus cogens. Pelo conteúdo primordial dessas normas, é patente que elas produzem seus efeitos sem necessidade da manifestação de vontade dos Estados, o que demonstra a relativização da soberania.

Palavras-chave: Jus cogens. Soberania. Subordinação.

Sumário: 1 Introdução - 2 Jus cogens - 3 Fundamentos do direito internacional público - 4 Soberania - $\mathbf{5}$ Conclusão - Referências

\section{Introdução}

Nos séculos XX e XXI, atos contra a vida humana ocorreram em grande intensidade na sociedade global. Por conta disso, uma nova consciência nasceu na população, fazendo a dignidade humana ser colocada como centro do debate jurídico.

Dessa maneira, com o escopo de se firmar uma nova ordem jurídica internacional baseada nos valores e interesses universais do ser humano (como também nele próprio), ganham espaço as normas jus cogens, que já detinham previsão consuetudinária, mas ganharam expressão textual na Convenção de Viena sobre Direito dos Tratados de 1969 (CVDT). 
De fato, o artigo 53 da CVDT reconhece que o jus cogens se apresenta como fonte do direito internacional, tendo aplicação obrigatória, sendo peremptório, inderrogável e imposto, reforçando o objetivismo no direito internacional. Tais normas seriam, assim, ungidas de princípios.

Para Lachs, o capítulo atinente ao jus cogens é o "mais fascinante do direito internacional contemporâneo", ${ }^{1}$ por expor a liberdade de ação estatal com limites.

E é nesse campo que busca caminhar o presente trabalho, tendo como objetivo desenvolver o conceito das normas de jus cogens, compreendendo que, mesmo existindo a soberania estatal, estas normas se impõem independentemente da decisão deles, sendo de observância obrigatória por reproduzirem valores reconhecidos por toda a comunidade internacional, devendo a soberania ser revisitada, superando-se o seu conceito absoluto.

Para tanto, o trabalho abordará as normas de jus cogens, o direito internacional público e a soberania. Ressalta-se que a abordagem metodológica é a hermenêutica jurídica, uma vez que se busca estabelecer o sentido e o alcance das normas jurídicas, como também compreendê-las de acordo com as situações sociais.

\section{Jus cogens}

\subsection{Surgimento do jus cogens}

É possível afirmar que, no momento em que o Estado começou a se formar, a estrutura individualista preponderava, ${ }^{2}$ ou seja, havia uma exacerbação da soberania. Porém, com o decorrer dos anos, a liberdade estatal recebeu limitações, uma vez que se passou a considerar nulo qualquer ato que violasse a ética e a ordem pública coletivas. ${ }^{3}$

Verdross ${ }^{4}$ afirma que a sociedade internacional anterior à Organização das Nações Unidas possuía barreiras à liberdade estatal para elaboração de tratados, já que os princípios gerais do direito reconhecidos por várias nações deveriam ser respeitados e obedecidos, o que pode ter evoluído para as normas de jus cogens, com repercussão em toda a comunidade internacional, que ganharam importância com o surgimento de desastres humanitários, pois, a partir deles, percebeu-se

LACHS, Manfred. The development and general trends of international law in our time. In: RCADI 169, IV (1980), p. 201.

2 VERDRROSS, Alfred. Forbidden Treaties in International Law. The American Journal of Internacional Law, v. 60,1966, p. 56.

3 Ibidem.

4 Ibidem. 
que deveria haver um mecanismo de âmbito internacional que buscasse aplicar normas independentemente das escolhas dos Estados, ${ }^{5}$ estabelecendo as bases para uma ética mínima universalmente estabelecida e com caráter legal, impondo limites à liberdade estatal. ${ }^{6}$

Segundo Salem Nasser, as normas de jus cogens "poderiam ser vistas como de ordem pública porque inderrogáveis pela vontade de Estados contratantes". ${ }^{7}$ Mas Nasser ressalta que não há clareza e definição quanto a essa vertente, pois o conceito e os efeitos extrapolam os definidos na CVDT, ${ }^{8}$ que não fez nascer as normas de jus cogens, porquanto apenas consolidou o que já existia no âmbito do direito internacional consuetudinário, ou seja, os "limites imperativos, de ordem pública, à autonomia jurídica dos Estados sob pena de invalidade das disposições dos atos jurídicos que os violassem", ${ }^{9}$ sempre tendo como vetor a proteção da dignidade humana.

\subsection{Características do jus cogens}

As normas de jus cogens fazem parte do direito internacional público na categoria específica de norma imperativa, de acordo com Nasser. ${ }^{10}$ O caráter imperativo do jus cogens vai além do conceito de obrigatoriedade normativa. Por tutelar interesses fundamentais comunitários e gerais da sociedade, bem como valores e interesses vitais a ela, ${ }^{11}$ a imperatividade é mais elevada e constringente, conforme Tatyana Friedrich. ${ }^{12}$

Assim, tais normas conferem legitimidade e validade às outras normas de direito internacional, podendo se afirmar que elas constituem uma forma de controle da legalidade supranacional ou que elas têm caráter de cláusulas pétreas

5 TRINDADE, Antônio Augusto Cançado. Memorial por um novo Jus Gentium, o Direito Internacional da Humanidade. In: Boletim da Sociedade Brasileira de Direito Internacional, Belo Horizonte, v. ago./dez. 2013, p. 9.

6 MOTA, Natállia Campos. O papel das normas jus cogens na hierarquia proposta pelo constitucionalismo internacional, 2013, p. 19. Disponivel em: <http://bdm.bce.unb.br/bitstream/10483/5885/1/2013_ Nat\%C3\%A1lliaCamposMota.pdf>. Acesso em: 15 fev. 2015.

7 NASSER, Salem Hikmat. Jus Cogens ainda esse desconhecido. Revista de Direito GV, v. 1, n. 21, p. 169, 2005. Disponivel em: <http://bibliotecadigital.fgv.br/dspace/bitstream/handle/10438/9658/Salem\%20 Hikmat\%20Nasser.pdf?sequence=1>. Acesso em: 12 maio 2015.

8 Ibidem.

9 FINKELSTEIN, Cláudio. Hierarquia das normas no Direito Internacional. Jus cogens e metaconstituiconalismo. São Paulo: Saraiva, 2013, p. 190-191.

10 NASSER, Salem Hikmat. Op. cit., p. 170.

11 Idem, p. 163.

12 FRIEDRICH, Tatyana Scheila. As normas imperativas de direito internacional público - Jus Cogens. 1. ed. Belo Horizonte: Editora Fórum, 2004, p. 34. 
mundiais. Isto é, as aludidas normas formam regras comuns que atendem às necessidades sociais mundiais e, por conta disso, direcionam objetivos de outras normas e só podem ser modificadas por normas de mesma natureza (são normas peremptórias). Esta ideia de supraconstitucionalidade também aparece na questão da preponderância da norma internacional sobre a interna. ${ }^{13}$

Em outras palavras, as normas de jus cogens, além de tutelarem um bem considerado indisponível, vinculando toda a comunidade internacional, possuem as características da inderrogabilidade e imutabilidade, salvo por norma de mesmo status jurídico, como afirmam João Grandino Rodas ${ }^{14}$ e Salem Hikmat Nasser. ${ }^{15}$

Logo, qualquer tratado que viole ou entre em conflito com norma imperativa de direito internacional geral é tido como nulo. ${ }^{16}$ Nesse sentido, Verdross defende que "são direitos taxativos aquelas normas de DI reconhecidas como tal por todos os povos civilizados, como o princípio de que não têm força obrigatória os tratados imorais e os que violam os princípios da humanidade (IX, B, II, $b, 5)$ ". ${ }^{17}$

\subsection{Quais normas são definidas como jus cogens?}

Não há uma lista específica das normas dessa categoria, cabendo, como disposto na CVDT, à Corte Internacional de Justiça - CIJ dispor a respeito. Em outras palavras, a CVDT não elenca exemplos de jus cogens, definindo apenas as condições para que uma norma assim seja estatuída: ser geral e capaz de vincular a maioria dos Estados, ser reconhecida e aceita pela maioria da comunidade internacional e não poder ser derrogada. ${ }^{18}$ Dessa forma, a CVDT concede à CIJ o poder de constituir as normas de jus cogens.

Exercendo seu papel, a CIJ reconhece os seguintes direitos como regras imperativas: principio do pacta sunt servanda, proibição ao genocídio, proibição à pirataria, proibição de atos que infrinjam a soberania e a igualdade dos Estados, proibição de atos contra a humanidade codificados nas quatro Convenções de

13 MELLO, Celso D. Albuquerque. Curso de Direito Internacional Público. 13. ed. v. 1. Rio de Janeiro: Renovar, 2001, p. 112.

14 RODAS, João Grandino. Jus cogens em direito internacional. Disponivel em: <http://www.revistas.usp.br/ rfdusp/article/download/66736/69346>. Acesso em: 01 mar. 2015.

15 NASSER, Salem Hikmat. Op. cit., p. 170.

16 ACCIOLY, Hildebrando; DO NASCIMENTO E SILVA, G. E.; CASELLA, Paulo Borba. Manual de Direito Internacional Público. 19. ed. São Paulo: Saraiva, 2011, p. 348.

17 (...) son de derecho taxativo aquellas normas del DI reconocidas como tales por todos los pueblos civilizados, como el principio de que no tienen fuerza obligatoria los tratados inmorales y los que violan los principios de humanidad (IX, $B, I I, b, 5)$ (VERDROSS, Alfred. Derecho Internacional Publico. Madrid: Aguilar, 1957, p. 81).

18 FINKELSTEIN, Cláudio. Op. cit., p. 184-185. 
Genebra, princípio da autodeterminação dos povos, proibição do uso ou da ameaça do uso da força, proibição do tráfico de escravos, proibição do emprego ilícito de força e execução de qualquer outro ato que constitua crime perante o direito internacional, princípio da soberania sobre recursos naturais, proibição de tráfico de seres humanos, princípios fundamentais dos direitos humanos e do direito do meio ambiente, proibição a atentados à paz, aos direitos inerente à independência e à autodeterminação das nações. De acordo com Guido Soares, ${ }^{19}$ as normas de jus cogens visam coibir graves violações (i) de obrigação internacional de importância essencial para a manutenção da paz ou da segurança internacionais, como a que proíbe a agressão; (ii) de uma obrigação internacional de importância essencial para o salvaguardo do direito à livre determinação dos povos, como a que proíbe o estabelecimento ou manutenção, pela força de uma dominação colonial; (iii) em grande escala de uma obrigação internacional de importância essencial para a salvaguarda do ser humano, como a que proíbe a escravidão, o genocídio e o apartheid; e (iv) de uma obrigação internacional de importância essencial para salvaguarda e proteção do meio ambiente humano, como a que proíbe a contaminação maciça da atmosfera dos mares.

Para João Grandino Rodas, ${ }^{20}$ "o jus cogens acoberta não só a proibição da escravidão, pirataria e tráfico de brancas, como também atentados ao direito à paz, aos direitos inerentes à independência e à autodeterminação das nações". Há outras normas na fila, como afirma Salem Hikmat Nasser, ${ }^{21}$ referindo-se a algumas normas do direito humanitário, dos direitos humanos e do direito do meio ambiente que pretendem receber status de jus cogens.

Ressalta-se, por fim, que alguns tratados ganharam o status de jus cogens, de forma que são obrigatórios independentemente da vontade dos Estados. São eles: Convenção de Combate à Escravidão (1928), Convenção sobre Genocídio (1948) e Convenção sobre a Eliminação de Todos os Tipos de Discriminação Racional (1965). ${ }^{22}$

\subsection{Jus cogens e as decisões judiciais}

A jurisprudência da Corte Internacional de Justiça - CIJ faz considerações a respeito das normas jus cogens da seguinte forma:

9 SOARES, Guido Fernando Silva. Curso de Direito Internacional Público. São Paulo: Atlas, 2002, p. 134.

20 LACHS, Manfred. The law of treaties (some general refletions of the report of the International Law Coimssion). In: Recueil d'Études de Droit International. En Hommage à Paul Guggenheim, Genebra, Faculdade de Direito de Genebra e Instituto de Altos Estudos Internacionais, 1968, p. 391.

21 NASSER, Salem Hikmat. Op. cit., p. 166.

22 ACCIOLY, Hildebrando; SILVA, G. E. do Nascimento e; CASELLA, Paulo Borba. Op. cit., p. 348. 
- Na Convenção para a prevenção e a repressão do crime de genocídio (1948), a Corte abordou que "os princípios, que estão na base da Convenção, são princípios reconhecidos pelas nações civilizadas, como vinculantes para os estados, mesmo fora de qualquer vínculo convencional" 23 (parecer consultivo de 28.05.1951, que foi reafirmado em 1996, no caso Bosnia v. lugoslávia).

- No Caso Corfu, afirma-se que as obrigações de jus cogens são fundadas sobre princípios gerais e bem assentados, como as considerações de elementar humanidade, mais absolutas ainda em tempo de paz do que em tempo de guerra, o princípio da liberdade das comunicações marítimas e a obrigação que incumbe a todo Estado não permitir a utilização de seu território para a realização de atos contrários aos direitos de outros Estados.

- No Caso Barcelona Traction, é realizada uma distinção entre obrigações jus cogens e erga omnes, essencial para serem conhecidas as obrigações dos Estados perante a comunidade internacional em seu conjunto e aquelas que nascem perante outro Estado no âmbito da proteção diplomática.

As normas jus cogens obtiveram sua primeira dimensão formal na CVDT, mas ganharam suas primeiras disposições declaratórias nas quatro Convenções de Genebra de 1969 (Convenção dos Feridos e Enfermos das Forças Armadas em Campanha, Convenção para Melhoria das Condições dos Feridos, Enfermos e Náufragos das Forças Armadas no Mar, Convenção Relativa ao Tratamento dos Prisioneiros de Guerra e Convenção Relativa à Proteção dos Civis em Tempo de Guerra).

No que toca à posição hierárquica, as normas de direito internacional não se colocam em patamares diferenciados, tendo em vista a descentralização do ordenamento jurídico. Situação diferente é a das normas de jus cogens, que teriam uma natureza de hierarquia superior ${ }^{24}$ por conta do reconhecimento de sua força peremptória e impassível de derrogação, oriunda do costume e da CVDT. ${ }^{25}$

Luigi Ferrajoli ${ }^{26}$ entende existir um direito constitucional internacional ou internacional constitucional, no qual teve sua pioneira materialização na Carta das Nações Unidas e na Declaração Universal dos Direitos do Homem de 1948.

23 CIJ, Recueil, 1951, p. 23 apud ACCIOLY, Hildebrando; SILVA, G. E. do Nascimento e; CASELLA, Paulo Borba. Op. cit., p. 144.

24 FINKELSTEIN, Cláudio. Op. cit., p. 206-207.

25 TRINDADE, Antonio Augusto Cançado. International Law for humankind: towards a new gentium (i). RCADI, 316, 2005, p. 26-27.

26 FERRAJOLI, Luigi. A soberania no mundo moderno. São Paulo: Martins Fontes, 2002, p. 53 e seguintes. 
Em razão disso, no caso de antinomias normativas em que se têm tanto o critério formal quanto o material para serem aplicados, é evidente que o jus cogens não deixará de ser considerado. Afinal, como para elaborar uma norma é fundamental observar e não violar as normas jus cogens, ambas as dimensões do critério formal - norma especial prevalece sobre geral e norma posterior prevalece sobre anterior - reconhecerão as normas imperativas, até porque os Estados não podem alegar o desconhecimento delas. Já quanto ao critério valorativo, que tem em seu bojo a ideia de que o conteúdo da norma deve ser considerado, o jus cogens também prevalece, haja vista que seu conteúdo se volta para a sociedade como um todo, para a ética e interesse comum universal.

O Projeto da Comissão de Direito Internacional das Nações Unidas sobre Responsabilidade Internacional dos Estados traz, em seu capítulo III, Parte do Projeto (Violações Graves de Obrigações Decorrentes de Normas Imperativas de Direito Internacional Geral), uma responsabilização especial (artigo 40 do Projeto) para os casos de infração a uma norma com status de imperativa no âmbito internacional.

Nesses casos, é necessário que os Estados, afetados ou não pela infração cometida, se reúnam para finalizar a violação por meio de mecanismos legais. Para Andrade, "é o dever de solidariedade que deve unir os membros da comunidade internacional, especialmente diante da gravidade da ofensa à ordem pública internacional". ${ }^{27}$

O direito humanitário é um exemplo de jus cogens. De fato, durante as guerras, as regras a serem respeitadas tinham como sustentação o costume, haja vista que a sistematização do direito humanitário somente ocorreu com a consolidação das Convenções de Genebra, devendo ser citado que a "cláusula de Martens" (Convenção II de Haia de 1899) foi um dos princípios dominadores dos direitos humanos por ser um mecanismo essencial capaz de fazer frente à evolução das técnicas militares. ${ }^{28}$

Assim, outorga-se proteção tanto aos civis quanto aos combatentes, ora soldados, motivo pelo qual as garantias são diferenciadas de acordo com as características de quem se busca tutelar. Segundo Dinh, Daillier e Pellet:

(...) Os primeiros não podem esperar uma certa solicitude senão após se encontrarem feridos ou feitos prisioneiros, os segundos devem a

27 ANDRADE, Isabela Piancetini. Responsabilidade Internacional do Estado por violação do jus cogens. Revista Brasileira de Direito Internacional, Curitiba, v. 5, n. 5, jan./jun. 2007, p. 24.

28 COMITÉ INTERNACIONAL DE LA CRUZ ROJA, 2002, p. 14, apud SANTOS, Thalyta dos. O direito internacional humanitário e a proteção dos prisioneiros de guerra. Disponível em:<http://www.unifebe.edu.br/revistadaunifebe/20121/artigo043.pdf>. Acesso em: 20 jan. 2015. 
todo momento ser poupados pelos horrores da guerra mas não estão protegidos como os combatentes postos fora de combate se eles participam episodicamente nos combates. ${ }^{29}$

Com isso, pode-se alegar que as principais regras de tal direito são: nenhum civil deve ser atacado; o ataque é apenas contra militares; meios e métodos de guerra não podem ser livremente escolhidos pelos Estados; feridos e prisioneiros em poder do Estado conflitante devem por ele ser tratados; é vedado o uso de mecanismos, como armas, que acarretem em perdas excessivas e desnecessárias; os civis presos pelo Estado conflitante devem se comunicar com suas famílias, bem como serem respeitados em sua dignidade, vida e crenças.

O objetivo deste direito é justamente regulamentar as condutas dos Estados que estão em conflito, não a ponto de findar a soberania de cada um deles ou, até mesmo, a guerra.

Através de regulamentação da conduta dos Estados em conflito, o Direito Internacional Humanitário se posiciona na mais delicada das searas estatais: a limitação da soberania, da livre vontade dos Estados. É por meio da normatização dos métodos de combate que o DIH lança regras que devem ser obedecidas pelos Estados combatentes, não para transformar a guerra em um jogo de regras elegantes pactuado por cavalheiros, mas sim para que a população civil não seja dizimada e ainda para que o conflito não leve a coletividade ao extermínio. ${ }^{30}$

Ademais, o direito humanitário unge-se de princípios, a saber: necessidade militar, humanidade, proporcionalidade, limitação e distinção. Por necessidade militar, entende-se que somente os mecanismos necessários é que devem ser utilizados para vencer e atacar o inimigo, é o realizar atos indispensáveis para vencer o inimigo, uma técnica bem-selecionada e pensada. A limitação encontra significado no fato de as partes poderem escolher meios e métodos de guerra, sendo certo que não podem atingir edifícios históricos ou religiosos, usar de meios desleais de combate, como armas que ensejem em dano desnecessário, depredar o meio ambiente, atingir a população e os bens civis etc. A proporcionalidade atrela-se ao resultado, ao equilíbrio, haja vista que não deve causar vítimas, nem danos excessivos. A distinção é uma norma consuetudinária, que se refere à

29 DIHN, Nguyen Quoc, DAILLER, Patrick e PELLET, Alain. Direito Internacional Público. Trad. Vitor Marques Coelho. Lisboa: Fundação Calouste Gulbenkian, 2003, p. 997.

30 SOUSA, Mônica Teresa Costa. Direito Internacional Humanitário. 2. ed. Curitiba: Jurua, 2007, p. 18. 
separação de um civil de um combatente, bem como o bem civil do objetivo militar. Já a humanidade tem relação com os direitos humanos, de sorte que, segundo a Declaração de São Petersburgo de 1868, a necessidade da guerra deve cessar antes da humanidade.

O direito humanitário é considerado um conjunto de normas de efeito erga omnes, imperativas e que, portanto, devem ser respeitadas. Normas que permitem exigir o cumprimento do Estado. Logo, é cediço que se trata de uma norma com status de jus cogens.

\section{Fundamentos do direito internacional público}

Buscar o fundamento de um direito é tentar compreender o motivo pelo qual ele tem força obrigatória. No caso do direito internacional público, por meio dos fundamentos, pretende-se entender as razões que fazem tal direito ser aplicável aos Estados soberanos. Assim, a fim de explicar a existência e a obrigatoriedade do supradireito, surgiram duas correntes: voluntarismo e objetivismo.

A égide da corrente voluntarista é o consentimento mútuo ou, como o próprio nome diz, a vontade dos Estados. Para Nguyen Quoc Dihn, Patrick Daillier e Alain Pellet, as regras são produto de uma vontade superior:

A defesa do voluntarismo jurídico utiliza argumentos mais concretos. Se o direito se impõe a todos os membros da colectividade, é porque emana de uma vontade que é superior, que ocupa a posição suprema no seio da sociedade. Qual é este ser superior? É o Estado. Ao designá-lo, os voluntaristas penetram o direito público. ${ }^{31}$

Dessa maneira, o voluntarismo busca expressar que o direito só existirá se o Estado prostrar-se a favor da criação e da elaboração de regras e normas, por meio de órgãos democráticos ou autoritários. Outra característica desta corrente é a autonomia, de modo que a obrigatoriedade de um direito não se subordina ao seu conteúdo. ${ }^{32}$

Logo, essa teoria tem como base a soberania estatal, haja vista que o direito apenas deriva de eventual vontade de um Estado. Nguyen Quoc Dihn, Patrick Daillier e Alain Pellet apresentam como um Estado soberano pode vincular-se pela sua própria vontade, colacionando as seguintes teorias: autolimitação do Estado,

31 DIHN, Nguyen Quoc; DAILLER, Patrick; PELLET, Alain. Op. cit., p. 100.

32 Idem, p. 101. 
vontade comum e procura de uma norma superior. Na primeira, o Estado não pode se subordinar a outra autoridade que não a sua, em razão de sua soberania; detém, assim, autodeterminação e autolimitação. “Essa autolimitação é conforme ao seu próprio interesse, pois se se vincula é a fim de responder às necessidades de uma comunidade internacional de que ele próprio é membro." ${ }^{33} \mathrm{Na}$ segunda, há uma menção à vontade comum e à isolada, sendo certo que a comum só se exterioriza mediante tratados ou costumes, pois a regra somente obriga quem participa. Na terceira, afirma-se existir uma norma superior que fundamenta a regra e permite que o Estado, se desejar, se vincule. Nesse âmbito, enfatiza-se que tal norma advém do princípio do pacta sunt servanda. ${ }^{34}$

No que concerne ao objetivismo, corrente que tem alusão à abstração e ao formalismo jurídicos, destaca-se que a concepção do Estado como detentor da vontade é meramente fictícia. "Entende Kelsen ser a comunidade internacional a 'ordem superior e comum que torna possível aos Estados se relacionarem' enquanto norma fundamental (Grundnorm)."35

As ditas normas imperativas acarretaram grandes inovações ao direito internacional, uma vez que, por um lado, evoluiu e, por outro, provocou resistência. Todavia, era fundamental a elaboração de normas incapazes de serem modificadas pela vontade do particular. A argumentação da teoria objetivista torna-se essencial, uma vez que não considera a soberania e a vontade estatal como centrais para a criação e elaboração de normas caracterizadas como primordiais para o mundo - normas capazes de fomentar uma ordem pública que atenda o interesse comum e que, portanto, são imodificáveis. Destaca-se que a Convenção de Viena sobre o direito dos tratados e sua consequente Convenção de Viena sobre tratados entre Estados e organizações internacionais ou entre organizações internacionais mencionam que as normas vistas como cogentes são impossíveis de serem derrogadas. As normas jus cogens expressam valores fundamentais da sociedade e ganharam a dimensão de inderrogáveis e cogentes (imperativas), como o próprio nome diz. Problemática em torno da aceitação do jus cogens se dá no fato de que alguns Estados ainda não o reconhecem ou procuram não conhecer, por conta de questões e interesses de âmbito interno, segundo suas próprias análises. Porém, ao aceitar a teoria objetiva, é cediço que a existência de normas cogentes internacionais será sua consequência. "A aceitação da objetividade do direito internacional exprime que existam e possam existir normas cogentes internacionais, independentemente da expressão da vontade e da aceitação de tais normas pelo estado." 36

Idem, p. 102.

34 Idem, p. 103.

35 ACCIOLY, Hildebrando; SILVA, G. E. do Nascimento e; CASELLA, Paulo Borba. Op. cit., p. 135-136.

36 Idem, p. 141. 
As normas imperativas de direito internacional geral possuem lugar no contexto pós-moderno, em categorias mais estáveis dos princípios gerais do direito internacional.

\title{
4 Soberania
}

O termo "soberania" advém das expressões em latim super omnia, superants e supremitas, cujas traduções são superior ou supremo. Seu surgimento encontra respaldo no pacto social, haja vista que ele permitiu a formação de um poder absoluto capaz de representar a vontade geral dos territórios. ${ }^{37}$

Grande parte das definições acerca da soberania não se dissocia do conceito de poder, uma vez que não se exerce o poder se não for soberano. De modo restrito, soberania é “(...) a qualidade de supremacia do poder, distinguindo este poder de todos os outros que, com ele, não podem concorrer". ${ }^{38}$ Ou seja, trata-se de uma autodeterminação estatal que se exterioriza principalmente na jurisdição, no qual cada Estado usa seu poder para apresentar soluções aos litígios Ihe apresentados e ocorrentes entre cidadãos. Nesse sentido, tem-se o pensamento de Dalmo Dallari:

\begin{abstract}
O primeiro aspecto importante a considerar é o que se refere ao conceito de soberania. Entre os autores há quem se refira a ela como um poder do Estado, enquanto outros preferem concebê-la como qualidade do poder do Estado, sendo diferente a posição de Kelsen, que, segundo sua concepção normativista, entende a soberania como expressão da unidade de uma ordem. Para Heller e Reale ela é uma qualidade essencial do Estado, enquanto Jellinek prefere qualificá-la como nota essencial do poder do Estado. Ranelletti faz uma distinção entre a soberania, com o significado de poder de império, hipótese em que é elemento essencial do Estado, e soberania com o sentido de qualidade do Estado, admitindo que esta última possa faltar sem que se desnature o Estado, o que, aliás, coincide com a observação de Jellinek de que o Estado Medieval não apresentava essa qualidade. ${ }^{39}$
\end{abstract}

37 FERNANDES, Luciana de Medeiros. Soberania \& Processos de Integração: o novo conceito de soberania em face da globalização - uma abordagem especial quanto às realidades de integração regional. Curitiba: Juruá, 2007, p. 52.

38 Idem, p. 52-53.

39 DALLARI, Dalmo de Abreu. Elementos de Teoria Geral do Estado. São Paulo: Saraiva, 2010, p. 79. 
Ainda acerca da definição de soberania, Luciana Medeiros Fernandes traz um entendimento mais compreensível. Transcreve-se:

A soberania é a idealização que vem indicar e qualificar o mais alto e determinante poder de ordenação e de comando, num dado território politicamente organizado, que não deriva seu fundamento de nenhum outro poder. Isto é, a qualidade de um poder que não admite qualquer limitação ou restrição ao seu exercício. Percebe-se, pois, que a soberania, normalmente, é concebida como um conceito de natureza essencialmente negativa, haja vista ser empregado para negar a existência de qualquer outro poder superior ao estatal, na seara interna, e para negar a possibilidade de limitação de sua igualdade e liberdade frente aos demais Estados, na seara internacional. ${ }^{40}$

Esclarece-se que a soberania, em que pese seja una, pode ser compreendida em dois âmbitos: interno e externo. O primeiro refere-se ao poder estatal no âmbito interno, ou seja, o Estado se autodetermina, legisla para todos os seus habitantes, administra seu espaço e órgãos de acordo com sua própria vontade e nos limites por ele mesmo traçados. É o Estado como autoridade suprema em face dos seus cidadãos, permitindo que aja como bem entender. ${ }^{41}$ Já no segundo, os Estado são independentes e devem se respeitar em todos os âmbitos, sem qualquer tipo de subordinação ou superioridade, predominando o princípio da igualdade soberana dos Estados descrito no artigo $2^{\circ}, \S^{\circ} 1^{\circ}$, da Carta das Nações Unidas, também denominado de princípio da não discriminação. Isso se dá porque o sistema jurídico internacional é horizontal, sendo os Estados soberanamente iguais entre si e sujeitos dos mesmos direitos e obrigações internacionais.

Pelo exposto, resta evidente que a soberania detém três dimensões: autoridade independente externa e interna, população e território. Além do que ela é capaz de dar o status de sujeito de direitos a um Estado.

\subsection{Características da soberania}

Conforme Luciana de Medeiros Fernandes, ${ }^{42}$ a soberania é composta pelas seguintes características: unidade, indivisibilidade, inalienabilidade, imprescritibilidade, originalidade e limitação.

40 FERNANDES, Luciana Medeiros. Op. cit., p. 54.

41 FERNANDES, Luciana Medeiros. Op. cit, p. 54-55.

42 Idem, p. 58-63. 
A soberania é una porque se manifesta em um único poder, não havendo mais de um ente absoluto e supremo. É indivisível por não poder se fatiada para não se desconfigurar, de sorte que o soberano congrega em si atribuições, prerrogativas e exigências. Prostra-se inalienável, uma vez que, se a soberania não existir, seus detentores (povo, estado, nação) desaparecem por ela representar a vontade geral - "o Estado perde a qualidade estatal" 43 quando alienado total ou parcialmente. Demonstra-se imprescritivel pelo fato de os atos do soberano serem contínuos e permanentes - "a soberania não poder perder a força com o tempo", ${ }^{44}$ inexistindo tempo de duração. Também é originária, pois se atrela a não derivação, de modo que o Estado soberano não está subordinado a condições e autorizações de outros poderes para que ninguém possa revogar suas decisões ou se mostrar mais soberano que ele. É, ainda, ilimitada, já que somente o próprio Estado pode se autolimitar. ${ }^{45}$

Complementando tais características, destacam-se os ensinamentos de Dallari:

A essas características acrescenta ainda ZANZUCCHI que a soberania é um poder: originário, porque nasce no próprio momento em que nasce o Estado e como um atributo inseparável deste; exclusivo, porque só o Estado o possui; incondicionado, uma vez que só encontra os limites postos pelo próprio Estado; coativo, uma vez que, no seu desempenho, o Estado não só ordena, mas dispõe de meios para fazer cumprir suas ordens coativamente. ${ }^{46}$

\subsection{Os limites da soberania}

O fenômeno da globalização permitiu não apenas o tráfego de pessoas, mercadorias, bens e capitais, como também ocasionou numa proximidade jurídica dos países. Esta aproximação foi de grande valia para a questão da soberania. Uma vez que se observou que o Estado não se encontrava sozinho, ao contrário, teve-se em mente que, além de existir inúmeros outros, os Estados criaram uma relação de independência e ganharam mais um limite para o seu governo soberano: o direito internacional.

43 Idem, p. 59

44 Idem, p. 60

45 FERNANDES, Luciana Medeiros. Op.cit., p. 58-63.

46 DALLARI, Dalmo de Abreu. Op. cit., p. 81. 
Em outras palavras, a soberania estatal, que já encontrava como obstáculos e limites a si o direito natural, os ideais de justiça, o bem comum mundial, a celeridade e o direito humanitário, recebeu como restrição os tratados, as convenções e os demais acordos firmados entre Estados que têm como principal fulcro e origem o direito internacional. ${ }^{47}$

Nguyen Quoc Dinh, Patrick Daillier e Alain Pellet abonam do entendimento de que os Estados devem se ater ao direito internacional:

\begin{abstract}
A este respeito, o sistema comunitário, por vezes qualificado de pré federal, aproxima-se ainda de uma confederação cujos Estados membros, embora renunciando a importantes prerrogativas da soberania - nas suas relações mútuas, mas também nas relações com países terceiros -, conservam a sua personalidade jurídica própria, portanto permanecem submetidos directa ou imediatamente ao direito internacional. ${ }^{48}$
\end{abstract}

Já no que diz respeito aos tratados internacionais, limitadores da soberania estatal, percebe-se sua essencialidade no fato de que as normas internas são parciais e restritas, uma vez que não consideram a universalidade humana, ao contrário das normas internacionais, que tratam das necessidades mais abrangentes da humanidade.

Além disso, no caso brasileiro, quando a CF/88 incorporou os direitos humanos, a soberania nacional absoluta foi relativizada. Afinal, trata-se de um documento que não foi elaborado pelo Congresso Nacional, mas que pertence à CF/88 - uma verdadeira flexibilização da soberania.

Ademais, o direito internacional também cria limites à soberania quando se fala em um sistema jurídico supranacional, no qual a um ente transnacional se concede a possibilidade de criar normas obrigatórias a todos os Estados, a todos os ordenamentos internos. Muitas dessas normas têm sido aplicadas por órgãos ditos como de caráter supranacional sem que sequer tenham sido recepcionadas ou validadas pelo ordenamento jurídico interno. ${ }^{49}$

Outro fator que demonstra a relativização da soberania são os processos de integração dos países, uma vez que "os Estados passam a admitir a coexistência de outras esferas legiferantes e decisórias fora das fronteiras estatais". ${ }^{50}$ Essas organizações são criadas pela vontade dos Estados, tendo atos, ordenamentos,

FERNANDES, Luciana Medeiros. Op. cit., p. 152.

48 DIHN, Nguyen Quoc; DAILLER, Patrick; PELLET, Alain. Op. cit., p. 435-436.

49 FERNANDES, Luciana de Medeiros. Op. cit., p. 153.

50 Idem, p. 259. 
vontades e personalidades próprias, relativizado a soberania, de modo que não persiste a alegação de prevalência do princípio do domínio reservado dos Estados, que consiste no fato de que as organizações não podem adentrar nas questões internas. Essas organizações, quando de integração, têm decisões vinculantes; já quando de cooperação, as decisões são intergovernamentais.

No mais, Enrique Pecourt Garcia ${ }^{51}$ compreende a soberania como igualitária e solidária. Na primeira, fala-se em uma coexistência das organizações políticas com os Estados; já a segunda aborda a existência de uma ordem jurídica superior aos Estados. No entanto, o aludido autor entende que a compatibilidade entre o direito internacional e o Estado seria a ocorrência da segunda hipótese - existência de uma ordem jurídica superior à dos Estados.

Enfatiza-se, ainda, que a soberania, segundo Dinh, Daillier e Pellet, tem consequência lastreada na questão da liberdade de ação estatal, que significa salientar as implicações jurídicas, permitindo o estabelecimento de competências e de direitos - enaltecendo que a independência estatal não pode ser vinculada somente às competências estatais internas, devendo considerar as repercussões interestatais. A liberdade de ação detém limites, a saber: o respeito ao direito internacional para garantir a soberania dos outros Estados; não intervenção (proibição da ingerência nos assuntos internos e a proibição do recurso à força); resolução pacífica de conflitos como uma alternativa real, oriunda e uma vontade geral de respeito ao direito internacional e da obrigação de cooperação; e o dever de cooperação nos domínios energéticos, como a economia e a formulação de mecanismos jurídicos adaptados à diversidade econômica e política. ${ }^{52}$

\subsection{Soberania e jus cogens}

Em virtude das catástrofes humanitárias sofridas e vivenciadas principalmente por conta da imposição autoritária, o direito internacional sofreu modificações. A grande necessidade do século XX foi a reconstrução do direito internacional considerando os direitos do ser humano balizados pela dignidade humana. Hoje, o mundo vive em uma constante reavaliação de conceitos importantes e de repercussão a toda a humanidade, principalmente aqueles atrelados ao próprio homem. Nesse sentido, transcreve-se trecho do ilustre Cançado Trindade:

51 GARCIA, Enrique Pelourt. La Soberanía de Los Estados Ante la Organización de Las Naciones Unidas (La Cláusula de Competencia Nacional em la ONU). Barcelona: Ediciones Sagitario, 1962, p. 29-30 apud FERNANDES, Luciana Medeiros. Op. cit., p. 263.

52 DIHN, Nguyen Quoc; DAILLER, Patrick; PELLET, Alain. Op. cit., p. 440-446. 
Seu denominador comum tem sido a atenção especial às condições de vida da população (particularmente dos grupos vulneráveis, em necessidade especial de proteção), dai resultando o reconhecimento universal da necessidade de situar os seres humanos de modo definitivo no centro de todo processo de desenvolvimento. Com efeito, os grandes desafios de nosso tempos - a proteção do ser humano e do ambiente, o desarmamento, a erradicação da pobreza crônica e das discriminações, a superação das disparidades alarmantes entre os países e dentro deles, e a busca do desenvolvimento do ser humano têm incitado à revitalização dos próprios fundamentos e princípios do direito internacional contemporâneo, tendendo a fazer abstração de soluções jurisdicionais e espaciais (territoriais) clássicas e deslocando a ênfase para a noção de solidariedade..$^{53}$

Os abusos cometidos contra os seres humanos despertaram na população uma consciência jurídica global, bem como tornaram evidente a necessidade de alterar o ordenamento jurídico internacional. Desse modo, no século XXI o primado do direito internacional não é mais o estatocentrismo, mas, sim, a pessoa humana como centro deste universo jurídico. ${ }^{54} \mathrm{O}$ ser humano passou a ser um limite ao tão grande poder soberano estatal; tanto é assim que qualquer decisão proferida pelos Tribunais deve considerá-lo. Além do mais, os direitos humanos promovem uma ponte entre o direito internacional público e o privado.

Movida pela consciência humana, a própria dinâmica da vida internacional contemporânea tem cuidado de desautorizar o entendimento tradicional de que as relações internacionais se regem por regras derivadas inteiramente de livre vontade dos próprios Estados. O positivismo voluntarista se mostrou incapaz de explicar o processo de formação das normas do direito internacional geral, e se tornou evidente que só se poderia encontrar uma resposta ao problema dos fundamentos e da validade deste último na consciência jurídica universal, a partir da afirmação da ideia de uma justiça objetiva, em benefício de todos os seres humanos. ${ }^{55}$

Buscando concretizar essa nova consciência, surgem as normas jus cogens, também chamadas de imperativas, conforme amplamente explanado. Tais normas

53 TRINDADE, Antônio Augusto Cançado. Memorial por um novo Jus Gentium, o Direito Internacional da Humanidade. In: Boletim da Sociedade Brasileira de Direito Internacional, Belo Horizonte, v. ago./dez. 2013, p. 9, 2013.

54 Idem, p. 11.

55 Idem, p. 13. 
incluem em seu bojo valores e interesses universais, capazes de atender os anseios do mundo, razão pela qual se prostram hierarquicamente superiores a qualquer outra norma ou fonte do direito internacional público. Assim, para um tratado ser criado, é fundamental que não viole as normas jus cogens, senão será inválido, o que também se aplica quando um tratado já foi sedimentado e, após, algum direito é reconhecido como jus cogens. No caso dos costumes, em que pesem inúmeras normas jus cogens deles se originarem, eles não podem relatar algo que viole a norma imperativa.

Com isso, as normas jus cogens, ao refletirem os valores compartilhados pela sociedade internacional, são verdadeiros princípios fundamentais do sistema jurídico que devem ser observados por todos os Estados. Afinal, refletem uma ideia universal e objetiva de justiça, superiores à vontade estatal.

Conforme Cançado Trindade, na realidade quando se reconhecem os princípios fundamentais que conformam o substrato da ordem jurídica em si, entramos no domínio do jus cogens, da lei imperativa. Esses princípios são indispensáveis (o jus necessarium); são anteriores e superiores à vontade dos Estados, porque expressam a ideia de uma justiça objetiva, própria do direito natural, e são consubstanciais à própria ordem jurídica internacional.

Ele aborda o "conteúdo expansivo do jus cogens", ou seja, sua natureza jurídica contendo valores fundamentais não o restringe ao direito dos tratados e à responsabilidade internacional dos Estados, o que ele chama de "expansão horizontal". Além disso, o jus cogens também está se expandindo em uma "dimensão vertical", da interação entre as normas jurídicas nacionais e internacionais no domínio atual da proteção. 0 efeito do jus cogens, neste segundo nível (vertical) tem sido no sentido de invalidar todo e qualquer ato legislativo, administrativo ou judicial, ao nível do direito interno dos Estados contrários ao jus cogens, como as leis que toleram a tortura, como aquelas de autoanistia. ${ }^{56}$

Em outras palavras, as normas imperativas são capazes de retirar a legitimidade de qualquer outra norma ou ato que a viole, seja de âmbito interno ou internacional.

As normas peremptórias também podem produzir efeitos jurídicos no âmbito do ordenamento jurídico interno do Estado - as normas internacionais de natureza jus cogens podem deslegitimar qualquer ato

56 FINKELSTEIN, Cláudio. Op. cit., p. 209. 
legislativo, administrativo ou judicial que autoriza a violação dessas normas hierarquicamente superiores, porque estão justamente acima da vontade do Estado. Essa incidência dos efeitos das normas peremptórias no âmbito do ordenamento jurídico interno dos Estados é o que Cançado Trindade chama de "dimensão vertical". ${ }^{57}$

Nesse esteio, há os ensinamentos de André de Carvalho Ramos:

De fato, é ilógico reduzir o conceito de jus cogens ao Direito dos Tratados. Se a comunidade internacional como um todo reconhece a existência de valores essenciais que não podem ser derrogados por outros tratados, a não ser que sejam também oriundos do jus cogens, é claro que esse reconhecimento se espalha para toda e qualquer conduta dos Estados, inclusive os atos unilaterais, a formação de costume etc. ${ }^{58}$

Esclarece-se que tais normas têm como fundamento o objetivismo, uma vez que não consideram a soberania e a vontade dos Estados como primordiais para a criação de normas com dimensão global e que são capazes de fomentar o interesse comum. Nesse âmbito, menciona-se também que o voluntarismo estatal foi limitado para proteger os direitos da pessoa humana, podendo-se dizer que o objetivismo deve ser a teoria mais aceita e aplicada.

A Corte Interamericana de Direitos Humanos, e.g., defendeu com firmeza e integridade do mecanismo de proteção da Convenção Americana sobre Direitos Humanos e impôs limites ao voluntarismo estatal, assegurando, desse modo, a salvaguarda dos direitos protegidos e a emancipação da pessoa humana vis-à-vis seu próprio Estado. ${ }^{59}$

Em virtude disso, é possível observar que, no novo cenário internacional, a soberania é limitada pelo jus cogens. Veja-se:

A consagração dessas obrigações representa a superação de um padrão de conduta erigido sobre a pretensa autonomia da vontade do Estado, do qual o próprio Direito Internacional buscou gradualmente se liberar ao consagrar o conceito de jus cogens.

57 Idem, p. 221.

58 RAMOS, André de Carvalho. Teoria Geral dos Direitos Fundamentais na Ordem Internacional. 2. ed. São Paulo: Saraiva, 2012, p. 141.

59 TRINDADE, Antônio Augusto Cançado. Op. cit., p. 15. 


\section{(...)}

No tocante a dimensão espacial, não mais visualizo o direito internacional como condicionado ao consentimento dos Estados territoriais. A repartição territorial de competências é simplesmente incapaz de resolver os problemas da comunidade internacional contemporânea. O novo jus gentium de nossos dias não se reduz ao que os Estados se mostram dispostos a conceder, essa visão anacrônica levou a fragmentação histórica do jus gentium no jus inter gentes. A teoria geral do direito baseada e centralizada no Estado e sua "vontade" mostrou-se incapaz de evitar a desagregação do gênero humano e as sucessivas atrocidades do século XX. Em definitivo, a nenhum Estado é dado considerar-se acima do direito internacional.

Com base na experiência internacional acumulada até o presente, a comunidade internacional não pode prescindir dos valores universais (...) comunidade internacional, a qual pressupõe a existência de interesses comuns e superiores, e deveres emanados diretamente do direito internacional (o direito das gentes) que a todos vinculam - os Estados, os povos e os seres humanos. ${ }^{60}$

André de Carvalho Ramos também se prostra nesse âmbito:

Assim, não basta que seja reconhecido o estatuto de jus cogens de determinada regra internacional. 0 conceito de jus cogens exige que o Estado se comporte de modo a respeitar seu conteúdo, não o derrogando com sua conduta comissiva ou omissiva. Logo, o desrespeito ao direito à autodeterminação por parte de um Estado deveria gerar reação da comunidade internacional como um todo, para que essa derrogação não prospere. ${ }^{61}$

Ora, segundo o acima exposto, é evidente que a mera argumentação de que, sem o consentimento dos Estados, as normas jus cogens não podem produzir efeitos, tampouco serem vistas como válidas, não prospera. As normas imperativas produzem, sim, seus efeitos e são válidas por serem as únicas criadas com o fundamento de salvaguardar os direitos inerentes à pessoa humana, a toda a comunidade e ao interesse (comum) internacional. A soberania é relativizada por meio do jus cogens, pois essas normas de hierarquia superior a todas as outras fontes do direito internacional (que são igualitárias) não permitem que o Estado a

$60 \quad$ Idem, p. 13-14.

61 RAMOS, André de Carvalho. Op. cit., p. 141. 
desconheça. Pode-se dizer que o jus cogens é fruto de um conjunto de ânimos e vontades estatais em proteger aquilo que entendem como essencial. Condições mínimas e comuns hoje tão almejadas pelo direito internacional.

O Estado, que se lastreia na liberdade de ação, possui como limitação a seus atos as normas jus cogens. Por isso, ainda que a soberania seja capaz de conferir direitos e deveres a um Estado, além de liberdade de ação, é certo que limites foram impostos a ela, como, por exemplo, a existência de normas peremptórias na Convenção de Viena de Direitos e Tratados, restrições estas que se categorizam como normas jus cogens e que se impõem aos Estados, independentemente de suas vontades, bem como pertencem aos direitos básicos da pessoa humana.

Assim, em que pese à soberania seja definida como autodeterminação estatal que não admite intervenção ou limitação, é certo que, com a globalização, tal circunstância foi alterada. Limites foram dados ao exercício da soberania, pois foi necessário proteger em maior amplitude os direitos dos seres humanos vistos como essenciais e comuns. A soberania foi relativizada para que se criasse um sistema supranacional com normas comuns e obrigatórias a todos os Estados e seus respectivos ordenamentos internos (como dito no tópico anterior e neste). A mencionada relativização foi, portanto, para poder atender os novos anseios, que tiveram origem com o próprio direito internacional: valores, interesses, princípios universais protegidos sem qualquer óbice. O próprio processo de integração mostrou essa necessidade de flexibilizar a soberania estatal.

Enfim, elucida-se que, pela teoria monista, também é possível verificar a relativização da soberania, sendo, assim, mais um fato indicativo da preponderância das normas imperativas.

Para o monismo, o Direito Internacional e o Direito Interno formam um conjunto, uma unidade jurídica, afastando a ideia de ordens jurídicas estanques, embora possam ser considerados ramos diferentes. Isto porque o fundamento do Direito, como um todo, encontra-se nos seus princípios gerais, enunciados de forma racional, com base nas ideias e, principalmente, em valores, como os da paz e da justiça. Dessa forma, a soberania estatal fica relegada a um segundo plano, exigindo-se uma nova leitura do seu papel, não mais preponderantemente político, e sim, cada vez mais, subordinado às exigências da solidariedade, da ética e da responsabilidade. ${ }^{62}$

62 SALA, José Blanes. A política internacional e as regras de jus cogens. Revista IMES-Direito, ano VIII, n. 13, jul./dez. 2007, p. 31. Disponível em: <http://www.corteidh.or.cr/tablas/22297.pdf>. Acesso em: 23 jan. 2015. 
Portanto, é impossível alegar que a soberania estatal prevalece sobre o jus cogens e que este último só tem efeito com a aceitação estatal. Para finalizar este entendimento, colaciona-se a seguinte afirmativa: "O próprio direito internacional, ao proclamar direitos inerentes a todo o ser humano - por definição, anteriores ou superiores ao Estado -, desautoriza o arcaico dogma positivista que pretendia autoritariamente reduzir tais direitos aos 'concedidos' pelo Estado". ${ }^{63}$

\section{Conclusão}

Conforme amplamente explanado, com o reconhecimento das normas jus cogens, a soberania do Estado que, até então, se dizia sem limites e com extensa liberdade de ação sofreu restrição. Houve o reconhecimento de que normas com carga valorativa altíssima, com viés protetivo sobre valores, direitos e interesses universais, devem ser respeitadas independentemente da aceitação estatal.

Alega-se que essas normas inderrogáveis formam a ordem pública internacional, além de comporem o que se denomina no âmbito interno de constituição (aquela que possui as normas mais importantes e de maior calão). Assim, em que pese não haja hierarquia formal entre normas internacionais, foi reconhecido que o jus cogens sempre prevalecerá por se encontrar numa posição superior às demais, tanto que as outras, ao serem elaboradas, devem observar e não violar a imperativa.

As normas jus cogens não possuem plena normatização. Ou seja, algumas encontram disposição na Convenção de Viena de 1969, porém, a maioria é assim categorizada pela jurisprudência. Dessa forma, elas estão presentes tanto nos costumes e jurisprudências da Corte Internacional de Justiça quanto em positivações jurídicas, como tratados e convenções.

Tamanha é a importância dessas normas que, por se tratar de uma questão de interesse coletivo, há um projeto que preza pela união dos Estados para punir a conduta do transgressor, de forma que os Estados, afetados ou não pelo ato, devem agir para findar a ação violadora (artigo 41 do Projeto "Violações graves de obrigações decorrentes de normas imperativas de direito internacional geral"). Uma responsabilização especial é atribuída ao violador.

Com isso, a pergunta a se fazer é: por que normas de tão grande escala geram discussões, como o ferimento da soberania?

A resposta é simples: os Estados desejam que seus interesses sejam mais bem atendidos, motivo pelo qual não querem ter limites de condutas. Eles prezam

63 TRINDADE, Antônio Augusto Cançado. Op. cit., p. 16. 
pela ausência de subordinação e limitação, porque isto facilitaria o desenvolvimento e progresso deles. No entanto, como podem os Estados pensarem desta forma, esquecendo que há valores sociais gerais e essenciais à população? Como podem os Estados quererem violá-los?

Afirmar que a soberania dos Estados é o que os move e que os faz serem assim reconhecidos é aceitável e correto. Contudo, em que pese se falar que a soberania promoveu uma autolimitação, a história mundial trouxe um limite universal para o fim de evitar novas tragédias. O homem foi colocado como centro do universo jurídico e, com a globalização promovendo uma intensificação e proximidade jurídica dos países, criou-se uma consciência universal de que o homem deve ser respeitado em qualquer lugar que esteja. Não se pode falar que um Estado é legítimo se, ao invés de prezar pela sua comunidade, a deturpa e viola os direitos dela.

A soberania estatal perde toda a sua legitimidade quando não respeita os valores, os interesses, os direitos já reconhecidos como necessários e fundamentais à população. A simples vontade do Estado não é capaz de evitar a desagregação humanitária, tampouco as atrocidades já ocorridas em outras décadas; por isso, não se pode ter o direito internacional como aquele que depende da vontade do Estado.

Dessa maneira, seja no âmbito interno, seja no internacional, quaisquer atos, normas, decretos etc. que forem criados, devem respeitar as normas jus cogens; caso contrário, serão considerados inválidos. É por conta disso que as supranormas são vistas como acima das demais e elencadas como de caráter supranacional ou, como já dito, são comparadas às constitucionais. Um instrumento jurídico que limita a liberdade de ação estatal para atender os anseios da comunidade internacional.

Enfim, não se pode alegar desconhecimento ou descumprimento das normas jus cogens tendo como justificativa a relativização da soberania dos Estados. Afinal, ainda que haja restrição, essas normas possibilitam o respeito à dignidade humana (norma reconhecida universalmente).

Portanto, é patente que as normas jus cogens limitam a liberdade contratual, as relações internacionais e os atos estatais, uma vez que impõem observâncias necessárias e fundamentais. Promovem uniformidade e padrões para que a dignidade humana seja respeitada. Ainda que se diga que acaba violando as culturas de cada país, se a dignidade é um valor primordial, devem-se ter normas capazes de consolidar o respeito por elas. 


\section{Jus cogens and the possible conflict with state sovereight}

Abstract: Abuse and lack of protection for man, highly evident in the I and II World Wars, made human dignity became the main concern of international society. One of the instruments that recognize such dignity and fundamental rights of human being are standards named as jus cogens. Because of the primary content of these standards, is patent that it produces effects without necessity to manifest the ill's States, what shows the sovereignty's relativize

Keywords: Jus cogens. Sovereignty. Subjection.

Summary: $\mathbf{1}$ Introduction - $\mathbf{2}$ Jus Cogens - $\mathbf{3}$ Grounds of public international law - $\mathbf{4}$ Sovereignty 5 Conclusion - References

\section{Referências}

ACCIOLY, Hildebrando; DO NASCIMENTO E SILVA, G. E. e; CASELLA, Paulo Borba. Manual de Direito Internacional Público. 19. ed. São Paulo: Saraiva, 2011.

ANDRADE, Isabela Piancetini. Responsabilidade internacional do estado por violação do jus cogens. Revista Brasileira de Direito Internacional, Curitiba, v. 5, jan./jun. 2007.

DALLARI, Dalmo de Abreu. Elementos de Teoria Geral do Estado. São Paulo: Saraiva, 2010.

DECRETO № 7.030, DE 14 DE DEZEMBRO DE 2009. Convenção de Viena sobre Direitos e Tratados.

DIHN, Nguyen Quoc; DAILLER, Patrick; PELLET, Alain. Direito Internacional Público. Trad. Vitor Marques Coelho. Lisboa: Fundação Calouste Gulbenkian, 2003.

FERNANDES, Luciana de Medeiros. Soberania \& Processos de Integração: o novo conceito de soberania em face da globalização - uma abordagem especial quanto às realidades de integração regional. Curitiba: Juruá, 2007.

FINKELSTEIN, Cláudio. Hierarquia das normas no direito internacional: jus cogens e metaconstituiconalismo. São Paulo: Saraiva, 2013.

FRIEDRICH, Tatyana Scheila. As normas imperativas de direito internacional público - jus cogens. 1. ed. Belo Horizonte: Editora Fórum, 2004.

LACHS, Manfred. The development and general trends of international law in our time. RCADI, 169, IV, 1980.

LACHS, Manfred. The law of treaties (some general refletions of the report of the International Law Coimssion). In: Recueil d'Études de Droit International. En Hommage a Paul Guggenheim, Genebra, Faculdade de Direito de Genebra e Instituto de Altos Estudos Internacionais, 1968.

MELLO, Celso D. Albuquerque. Curso de Direito Internacional Público. 13. ed. Rio de Janeiro: Renovar, 2001. 
MOTA, Natállia Campos. O papel das normas jus cogens na hierarquia proposta pelo constitucionalismo internacional, 2013. Disponível em: <http://bdm.bce.unb.br/ bitstream/10483/5885/1/2013_Nat\%C3\%A1lliaCamposMota.pdf>. Acesso em: 15 fev. 2015.

NASSER, Salem Hikmat. Jus Cogens ainda esse desconhecido. Disponível em: <http:// bibliotecadigital.fgv.br/dspace/bitstream/handle/10438/9658/Salem\%2OHikmat\%20 Nasser.pdf?sequence=1>. Acesso em: 12 maio 2015.

Projeto "Violações graves de obrigações de correntes de normas imperativas do direito internacional geral". Disponivel em: <http://novodireitointernacional.com.br/wp-content/ uploads/2012/02/Projeto-da-CDI-sobre-Responsabilidade-Internacional-dos-Estados.pdf>. Acesso em: 22 fev. 2015.

RAMOS, André de Carvalho. Teoria Geral dos Direitos Humanos na Ordem Internacional. 2. ed. São Paulo: Saraiva, 2012.

RODAS, João Grandino. Jus cogens em direito internacional. Disponível em: <http://www. revistas.usp.br/rfdusp/article/download/66736/69346>. Acesso em: 01 mar. 2015.

SALA, José Blanes. A política internacional e as regras de jus cogens. Revista IMES-Direito, ano VIII, n. 13, jul./dez. 2007. Disponível em: <http://www.corteidh.or.cr/tablas/22297. pdf>. Acesso em: 23 jan. 2015.

SANTOS, Thalyta dos. $O$ direito internacional humanitário e a proteção dos prisioneiros de guerra. Disponível em:<http://www.unifebe.edu.br/revistadaunifebe/20121/artigo043. pdf>. Acesso em: 20 jan. 2015.

SOARES, Guido Fernando Silva. Curso de Direito Internacional Público. São Paulo: Atlas, 2002.

SOUSA, Mônica Teresa Costa. Direito Internacional Humanitário. 2. ed. Curitiba: Juruá, 2007.

TRINDADE, Antônio Augusto Cançado. Memorial por um novo Jus Gentium, o Direito Internacional da Humanidade. Boletim da Sociedade Brasileira de Direito Internacional, Belo Horizonte, v. ago./dez. 2013.

VERDROSS, Alfred. Derecho Internacional Publico. Madrid: Aguilar, 1957.

VERDRROSS, Alfred. Forbidden Treaties in International Law. The American Journal of International Law, v. 60, 1966.

Informação bibliográfica deste texto, conforme a NBR 6023:2002 da Associação Brasileira de Normas Técnicas (ABNT):

VEDOVATO, Luís Renato; ANGELINI, Maria Carolina Gervásio. o jus cogens e o possível conflito com a soberania do Estado. Direitos Fundamentais \& Justiça, Belo Horizonte, ano 10, n. 35, p. 103-126, jul./dez. 2016. 